\title{
Una fuente portuguesa de "El reino interior"
}

\begin{abstract}
A L reconocer la deuda evidente de Darío a las fuentes francesas, muchos críticos desatienden la posibilidad de influencias de otros países. Sin embargo, para trazar con exactitud los origenes de su compleja poesía habría que tener en cuenta los múltiples aspectos de sus gustos cosmopolitas, sólo parcialmente expresados en su interés crítico por escritores portugueses, italianos, alemanes, noruegos, belgas y norteamericanos, para nombrar solamente los que se incluyen en Los raros. Nuestra nota quiere señalar solamente una de esas posibles influencias, el poeta portugués, Eugenio de Castro, para documentar mediante una comparación de dos poemas lo que puede ser un significativo paralelo entre los dos escritores.

El principal punto de contacto entre los dos, desde una perspectiva histórica, es el ensayo de Dario sobre Castro incluido en Los raros, un libro publicado — con una significación simbólica para la comparación que aquí establecemos- en el Día de la Raza, r896. Castro no exageraba la importancia de este ensayo cuando escribió en su autobiografía que a ese estudio y a la traducción de Belkiss por Luis Berisso con su prefacio por Leopoldo Lugones, se debió principalmente su reputación en Hispanoamérica. Igualmente podría haber reconocido dicho ensayo de Darío como fuente de gran parte de su prestigio en España. ${ }^{1}$ A excepción de unas breves notas agradeciéndose mutuamente el envío de libros, su amistad era más bien literaria que personal, pues no llegaron a encontrarse nunca.

El elogio de Darío apenas podría ser más entusiasta. Tras un largo prefacio en que lamenta el golfo que separa las culturas española y

1 Eugénio de Castro, "Una autobiografía literaria, II", La Nación (Buenos Aires), 11 mayo 1924. Véase también Tohn M. Fein, "Eugénio de Castro and the Introduction of Modernismo to Spain"; PMLA, LXXIII (diciembre, 1958), 356.561 .
\end{abstract}


portuguesa, empieza su discusión de la obra de Castro calificándolo como un artista que era "uno de los más exquisitos con que hoy cuenta... la moderna literatura cosmopolita".2 Evidentemente Darío intuyó que los fines de Castro, sus métoçss, valores y preferencias literatias, se relacionaban estrechamente con los suyos y con los gustos del naciente movimiento modernista. Alabanzas especiales merecieron la delicadeza de temas de Castro, la brillantez de sus imágenes, y su versificación musical. Darío concluyó su ensayo - que originalmente dio como conferencia unas semanas antes en el Ateneo de Buenos Aires- leyendo varios largos pasajes de las obras de Castro. Tanto la fuente de su entusiasmo, como su naturaleza, se incluyen en una explicación de su reciente contacto con la obra del poeta portugués:

¿Ha tenido que luchar Eugenio de Castro? Indudablemente, sí. No conozco los detalles de su campaña intelectual, pero no impunemente se llega a tan justa gloria a su edad, ai se producen tan admirables poemas... No he leído sus obras sino después que conocía al poeta por la critica de Italia y Francia. Abonado por Rémy de Gourmont y Vittorio Pica, encontró abiertas de par en par las puertas de mi espíritu. Leí sus versos. Desde el primer momento reconocí su iniciación en el nuevo sacerdecio estético, y la influencia de maestros como Verlaine. ${ }^{3}$

La admiración de Darío se expresa concretamente en su dedicatoria de "El reino interior" a Eugenio de Castro. Más aún, aunque no conocemos los meses exactos en que los distintos poemas de Prosas profanas fueron escritos, la posición de "El reino interior" al final del libro sugiere que podría haberse compuesto hacia las fechas de su conferencia sobre Castro, que ocupa una posición similar en Los raros, y del que sabemos que fue el último ensayo que hizo para tal colección.

Otra expresión de Los raros nos proporciona un nuevo indicio de la fuente portuguesa: "Después llegó a mis manos, en el Mercure de France, un poema simbólico y extraño, de un sentimiento profundamente pagano, hondo y audaz. Sagramor y Belkiss me hechizaton luego"." Salvo una crítica entusiasta en I896 de Rémy de Gourmont (sin duda la aludida anteriormente por Darío), incluyendo unos pocos pasajes traducidos de Silva, la única traducción de la obra de Castro en el Mercure de France antes de 1896 fue una versión anónima de "Hermafrodita" en $1895 . .^{5}$ Ciertamente los términos que Darío emplea al describirla la caracterizan

2 Rubén Dario, Los ratos (Santiago de Chile, 1942), p. 207.

3 Ibidi, pp. 208-209.

4 Ibit, p. 210 .

5 "Hermiphrodite", Mercure de France, XIII (enero, 1895), 42-46. 
claramente, y no podrían aplicarse a los fragmentos de Silva. Ya a través de la traducción de "Hermafrodita", o directamente del original, o quizás de ambos, Darío debió sentir su impresión en forma duradera.

No cabe duda de que un poema de Verlaine es una de las fuentes de "El reino interior"; Darío lo adaptó mediante un tratamiento prerafaelita. Darío mismo observó que "en 'El reino interior' se siente la influencia de la poesía inglesa de Dante Gabriel Rossetti y de algunos de los corifeos del simbolismo francés". "Mapes fue el primero en observar la referencia del poema al "Crimen amoris" de Verlaine, aunque reconociendo que sólo se usaba parcialmente:

La plupart des détails de description de ces personnages, qui sont un des charmes principaux du poème de Dario, manquent chez Verlaine et bien que l'une et l'autre composition représentent la lutte dramatique du bien et du mal dans l'âme humaine, la ressemblance se borne aux généralités. Ici, comme presque toujours, Darío est un artiste trop raffiné pour tirer toute son inspiration d'une seule source, si bonne qu'elle soit. ${ }^{7}$

Los jóvenes demonios de "El reino interior" tienen evidentemente su origen en el "Crimen amoris". No sólo se localizan, como en éste, en Ecbatana, sino que se describen de modo similar:
Dans un palais, soie et or, dans Ecbatane,
De beaux démons, des Satans adolescents,
Au son d'une musique mahométane,
Font litière aux Sept Péchés de leurs cinq sens.

Tras cuatro estanzas Verlaine abandona la descripción del grupo para concentrarse en "le plus beau d'entre tous ces mauvais anges", en el que varios críticos han visto cierto parecido con Rimbaud. El resto de las veinticinco estanzas tratan de él, concluyendo con su quema del palacio satánico en un sacrificio incendiatio, y con la escena pacífica de la naturaleza ofreciendo a Dios la oración del poeta. En ninguna parte, salvo en ciertas referencias a voces mujeriles y demonios femeninos, encontramos figuras de mujeres, ni hay antecedente personal alguno de la infanta de Darío.

Marasso observó la influencia en "El reino interior" de los cuadros de Boticelli, junto con la de Verlaine, así como ciertas reminiscencias de

6 Arturo Marasso, Rubén Dario y su creación poética (Buenos Aires, 1954), p. 142 .

7 Erwin K. Mapes, L'Influence française dans l'oeuvre de Rubén Dar?o (Paris, 1925), p. 74. Véase el estudio comparativo de Edmundo De Chasca, en $N^{\circ}$ 41-42, pp, 309-317. 
"La prisionnière" de Richepin (en Mes Paradis, 1894) y de Au jardin de l'infante (I893) de Samain. Estos poemas pueden haber influido en la creación de la "infanta mistetiosa" de Darío, que es la proyección de su alma y a quien se alude en el epígrafe de Poe, "With Psyche, my Soul". 8

Ninguna de estas fuentes, sin embargo, alude al conflicto que la infanta de Darío experimenta al final del poema, y. en el que se incorpora la dualidad que es la culminación de toda la composición:

$Y$ en sueños dice: "¡Oh dulces delicias de los cielos! ¡Oh tierra sonrcsada que acarició mis ojos!

- ¡Princesas, envolvedme con vuestros blancos velos!

- Príncipes, estrechadme con vuestros brazos rojos!"

En esta respuesta a la previa interrogación del poeta, la infantr pasa de las abstracciones de las virtudes y los vicios (la primera y segunda líneas de la cita anterior) a las exclamaciones concretas de las líneas tercera y cuarta, así como pasa del ambiguo "envolved" a las asociaciones sexuales concretas de "estrechad". Aunque la intención alegórica de reflejar vicio y virtud en equilibrio sigue siendo la primaria en el poema, se expresa en su forma más concreta en la dualidad entre "princesas" y "príncipes", símbolos de feminidad y masculinidad. El elemento sexual se introduce inesperadamente, a pesar de una premonición: "Y los siete mancebos a las siete doncellas/lanzan vivas miradas de amor. Las Tentaciones". Lo que es significativo es que la reacción física de la infanta no sea la normal que podríamos esperar. Antes de las lineas finales precitadas, el poeta formula la pregunta que podría esperarse del lector:

-iOh! ¿Qué hay en ti, alma mía?

¿Oh! ¿Qué hay en ti, mi pobre infanta misteriosa?

¿Acaso piensas en la blanca teoría?

¿Acaso

los brillantes mancebos te atraen, mariposi?

Ella no me responde.

Sólo más tarde, en sus sueños, expresa la infanta su conflicto subconsciente. La reacción física de la infanta sólo a los jóvenes podría ser psicológicamente adecuada, pero destruiría el propósito del poeta de reflejar alegóricamente la igual atracción del vicio y la virtud. Para ha-

8 Marasso, p. 140. 
cerlo debe dotar a la infanta de una naturaleza doble, y sugerir su anhelo por ambos símbolos, el masculino y el femenino.

Es precisamente esta doble naturaleza, combinada con anhelo y conflicto entre ambas mitades, lo que contribuye el tema de "Hermafrodita" de Castro (Salomé e outros poemas). Siguiendo en parte la versión de Ovidio de la leyenda (con la excepción de que en la versión de Castro ambos amantes piden a los dioses su unión, en vez de hacerlo sólo Salmacis), Castro introdujo el largo poema con una escena de amor que culmina en el ruego de los amantes:

De Hermes e de Afrodite o filho esbelto e amado,

De Salmacis oscula o corpo melodioso,

E a ninfa treme e enleia o moço deslumbrado,

Com um prazer que até chega a ser doloroso.

Ela-dócil, a arfar, como, ao vento, as searas...

Ele-forte, a arquejar, como, com cio, um touro...

O cabelo da ninfa inunda as duas caras,

E há beijos musicais sob essa chuva de ouro.

¿Enleados um ao outro, a asa de uma môsca

Não caberia não! entre êsses corpos belos,

Que se enroscam, sensuais, febris, como se enrosca

No tronco a vide em flor, e a hera nos castelos.

Dos dois corpos a união, entre lascivos ais, Cada vez, cada vez se torna mais completa, E aquelas coxas cada véz se agitam mais:

Umas brancas, de luar, outras rijas, de atleta.

Num doido frenesi, entrar parecem qu'rer

Ela-no corpo dêle, êle-no corpo dela!

Choram, gemen, dão ais ... e no auge do prazer,

Começam a gritar para o céu que se estrela:

- OO Deuses! atendei esta súplica ardentes

"Se é verdade que ouvis at vozes que vos chamam,

"Os nossos coragóes, fundi-os os num sòmente,

"Fundi num corpo só nossos corpos que se amam!"

Tras otorgar Zeus su ruego, el resto del poema describe -gráfica y a veces conmovedoramente - el conflicto interior de la pareja unida en un cuerpo: 
A bôca féminil abre-se doida, ansiosa Por belos deuses nus, mas sem os encontrar; E os braços, procurando uma cintura airosa Abrem-se, mas em văo! dão abraços no ar!

Pede o seio lirial beijos de gladiador, Pede a fronte viril, de mils virgens os beijos; $\mathrm{E}$ assim, no mesmo corpo, em ímpetos de amor, Debatem-se, febris, dois desiguais desejos.

¡Sao dois leões rivais prescs na mesma cova! $¡$ Rugem, brandem punhais, corre o sangue escarlate!

¡E o corpo (árvore e flor!), que o infortúnio corcova, i'sStremece, ao estremecer dêsse rubro combate!

Al concluir el poema de Castro, Hermafrodita, insoportablemente dividido por las dos direcciones sexuales, muere. Como en el caso de las princesas de Darío en "El reino interior", sin embargo, la Iucha continúa indecisa en el alma del poeta:

Sem poder sofrer mais desespêro tamanho,

Hermafrodita un dia emfrim, crispando as mãos,

Enforçou-se e morreu .... mas do seu corpo estranho

Saíram, sempre hostis, os dois feros irmãos.

Chovia ... E procurando uma guarida calma,

Que os livrasse da chuva, uma tôtre ou uma gruta,

Viram minh'alma aberta, entrarm na minh'alma,

¡E na minh'alma estão continuando a luta!

Sin duda Darío recordaba inconscientemente el poema de Castro cuando escribía la conclusión de "El reino interior", así como refleja inconscientemente numerosas fuentes en muchos de sus poemas. Que tal asociación no sólo existió, sino que persistió en su mente, lo muestra la unión de una de las mejores caracterizaciones de Castro, Belkiss, con una referencia a Hermafrodito en un poema escrito en I90I, "Otro dezir":

Un camarín te decoro

donde sabtás la lección

que dio a Angélica Medoro

y. a Belkiss dio Salomón;

arderá mi sangre laca,

$y$ en el vaso de tu boca

te sorberé el corazón. 
Luz de sueño, flor de mito,

tu admirable cuerpo canta

la gracia de Hermafrodito

con lo aéreo de Atalanta;

Por lo menos cinco años después de su inicial entusiasmo por la obra de Castro, Darío recuerda - quizás conscientemente ahora- dos de los más originales trabajos del jefe del movimiento simbolista en Portugal.9

La utilización inconsciente de Castro evidentemente no disminuye el mérito artístico de uno de los mejores poemas de Darío. Sin duda hay suficiente diferencia en el tratamiento del tema, especialmente la multiplicación de los símbolos masculino y femenino en grupos paralelos de siete, para dar amplio margen a las dotes poéticas de Darío. Más que disminuir su originalidad, la influencia de Castro denota la flexibilidad y equilibrio con que Darío asimilaba la mejor poesía de las fuentes más diversas. Su capacidad para hacerlo con éxito es quizás su mayor originalidad.

Duke University

JOHN M. FEIN

9 Las "manos liliales" de "El reino interiot" que Mapes (p. 87), considera una influencia de Hugo bien puede ser - por su frecuencia en la obra de Castro y por su empleo en "Hermafrodita" - otra evidencia de la lectura del poeta portugués. Otra posible influencia de Castro es la de las expresiones que Mapes denomina "mots d'apothéose" (p. 88), atribuida a Banville. 
